S. Nair · Y. H. Lee - E. Rousseau - M. Cam - P. A. Tataranni - L. J. Baier •

C. Bogardus $\cdot$ P. A. Permana

\title{
Increased expression of inflammation-related genes in cultured preadipocytes/stromal vascular cells from obese compared with non-obese Pima Indians
}

Received: 30 December 2004 / Accepted: 28 April 2005 / Published online: 21 July 2005

(C) Springer-Verlag 2005

\begin{abstract}
Aims/hypothesis: The specific contributions made by the various cell types in adipose tissue to obesity, particularly obesity-related inflammation, need to be clarified. The aim of this study was to elucidate the potential role of adipocyte precursor cells (preadipocytes/stromal vascular cells [SVC]). Methods: We performed Affymetrix oligonucleotide microarray expression profiling of cultured abdominal subcutaneous preadipocytes/SVC isolated from the adipose tissue of 14 non-obese (BMI $25 \pm 4 \mathrm{~kg} / \mathrm{m}^{2}$ ) and 14 obese $\left(55 \pm 8 \mathrm{~kg} / \mathrm{m}^{2}\right)$ non-diabetic Pima Indian subjects. Quantitative real-time PCR (RT-PCR) was used to verify the differential expression of several genes in an independent group of subjects. Results: We identified 218 differentially expressed genes with $p$ values less than 0.01 . Microarray expression profiling revealed that the
\end{abstract}

Electronic supplementary material Supplementary material is available for this article at http://dx.doi.org/10.1007/s00125-0051868-2 and accessible for authorised users.

S. Nair $(\bowtie) \cdot$ Y. H. Lee · E. Rousseau · P. A. Tataranni ·

L. J. Baier - C. Bogardus

Obesity and Diabetes Clinical Research Section,

Phoenix Epidemiology and

Clinical Research Branch,

National Institute of Diabetes and

Digestive and Kidney Diseases,

National Institutes of Health,

4212, N. 16th St.,

Phoenix, AZ, 85016, USA

e-mail: snair@mail.nih.gov

Tel.: +1-602-2005361

Fax: +1-602-2005335

M. Cam

National Institute of Diabetes and

Digestive and Kidney Diseases,

National Institutes of Health,

Bethesda, MD, USA

P. A. Permana

Carl T. Hayden Veterans Affairs Medical Centre,

Phoenix, AZ, USA expression of inflammation-related genes was significantly upregulated in preadipocytes/SVC of obese individuals. Quantitative RT-PCR confirmed the upregulation of IL8, CTSS, ITGB2, HLA-DRA, CD53, PLA2G7 and MMP9 in preadipocytes/SVC of obese subjects. Conclusions/ interpretation: The upregulation of inflammation-related genes in preadipocytes/SVC of obese subjects may increase the recruitment of immune cells into adipose tissue and may also result in changes in the extracellular matrix (tissue remodelling) to accommodate adipose tissue expansion in obesity.

Keywords Adipocyte - Adipose tissue - Gene expression · Inflammation - Microarray · Obesity · Obesity-related inflammation - Preadipocyte - Stromal vascular cells · Tissue remodelling

Abbreviations ESM: electronic supplementary material . RT-PCR: real-time polymerase chain reaction -

SVC: stromal vascular cells

\section{Introduction}

As the major cell type of adipose tissue, adipocytes secrete several proinflammatory cytokines that may contribute to inflammation associated with obesity $[1,2]$. We have recently demonstrated increased levels of expression of inflammation genes in adipocytes of obese Pima Indian subjects [3].

In addition to adipocytes, adipose tissue contains cell types such as preadipocytes/stromal vascular cells (SVC), mesenchymal stem cells, macrophages, endothelial cells and fibroblasts. These various cell types may play different roles in adipose tissue inflammation associated with obesity. For example, it has been postulated that macrophages resident in adipose tissue contribute to obesity-associated inflammation and insulin resistance $[4,5]$. Furthermore, it has been shown that preadipocytes/SVC can function as 
macrophage-like cells and may play a direct role in inflammation response and obesity $[6,7]$.

In this study, we compared the gene expression profiles of cultured abdominal subcutaneous preadipocytes/SVC from obese and non-obese non-diabetic Pima Indians to determine the potential role of this cell type in obesity, particularly in obesity-related inflammation.

\section{Subjects, materials and methods}

Subjects, metabolic measurements and fat biopsies The subject selection criteria, metabolic measurements and fat biopsies are described in detail in the accompanying manuscript [3]. The anthropometric and metabolic variables of the subjects who participated in the preadipocyte experiments are described in Table 1, while the measurements for the subjects who took part in the adipocyte experiments are detailed in the accompanying manuscript [3].

Preadipocyte isolation and culture Collagenase digestion of the subcutaneous abdominal adipose tissue biopsy samples was carried out as described previously [8]. The floating adipocytes were isolated as described by Lee et al [3]. The preadipocyte-containing infranatant was collected into a separate tube and washed several times with Hank's Balanced Salt Solution. The stromal vascular fraction pellet containing preadipocytes/SVC was resuspended in standard medium consisting of Medium 199 (Life Technologies, Grand Island, NY, USA) supplemented with $1 \mu \mathrm{g} / \mathrm{ml}$ amphotericin B, $100 \mathrm{U} / \mathrm{ml}$ penicillin $\mathrm{G}$ sodium, $100 \mu \mathrm{g} / \mathrm{ml}$ streptomycin sulphate, $2 \mathrm{mmol} / 1$ Glutamax-1 and $10 \%$ heat-inactivated FBS (Life Technologies). The suspension was strained through a sterile $25-\mu \mathrm{m}$ stainless steel tissue sieve (Thermo EC, Holbrook, NY, USA). The filtrate was transferred to a T75 culture flask and maintained in an incubator at $37^{\circ} \mathrm{C}$ in $5 \% \mathrm{CO}_{2}$. Cells were allowed to attach and, the next day, floating red blood cells were removed by aspiration and the culture media was replenished. At sub-confluency, the cultured cells were trypsinised and plated at a concentration of approximately $1.5 \times 10^{6}$ cells $/ 15-\mathrm{cm}$ dish for RNA extraction, which was carried out approximately 14 days after the biopsy date. Media was changed every 2-3 days throughout the culturing period. There were no differences (in terms of cell number or visible morphology) between the cultures from the non-obese and obese subjects.

Microarray Microarray analyses were carried out on approximately 33,000 genes represented by approximately 45,000 probe sets on Affymetrix Genechip arrays (HGU133 A and B; Santa Clara, CA, USA) in 14 non-obese and 14 obese Pima Indian subjects. Target preparation, array hybridisation and scanning and processing were as described in Lee et al [3]. The data for absolute analysis have been deposited in NCBI Gene Expression Omnibus (GEO; http://www.ncbi.nlm.nih.gov/geo/, GEO Series accession number GSE2510).

Quantitative real-time PCR Quantification of transcripts was carried out using TaqMan Assays-on-Demand Gene Expression Products (Applied Biosystems, Foster City, CA, USA) as described previously [8] in an independent group of subjects (Table 1). The mRNA levels of each gene were normalised to those of the gene encoding the TATA-box binding protein $(T B P)$ as described in the preceding article [3]. Ten subjects (six non-obese and four obese) were members of both independent subject groups for quantitative RT-PCR in preadipocytes (Table 1) and adipocytes [3], i.e. preadipocytes and adipocytes were simultaneously isolated from these ten individuals. The clinical characteristics of the two independent subject groups were not statistically different.

Statistical analyses The anthropometric characteristics of the subjects who participated in the microarray study and the independent group of subjects who took part in the quantitative RT-PCR experiment were statistically analysed using the Student's $t$-test and Wilcoxon tests (Statistical Analysis System software, SAS Institute, Cary, NC, USA). The Mann-Whitney U-test (MAS5.0, Affymetrix) was carried out to analyze differentially expressed genes in the microarray data. Q-RT-PCR data of selected inflammation-related genes between cultured preadipo-
Table 1 Clinical characteristics of the subjects who participated in the microarray and quantitative RT-PCR confirmation studies

The data are shown as means \pm SD

${ }_{\mathrm{b}}^{\mathrm{a}} p \leq 0.01$ vs non-obese subjects

$\mathrm{b}_{n=9}$

${ }^{\mathrm{c}} n=8$

\begin{tabular}{lcccc}
\hline Characteristic & \multicolumn{2}{l}{ Microarray } & & \multicolumn{2}{l}{ Quantitative RT-PCR } \\
\cline { 2 - 3 } \cline { 5 - 6 } & $\begin{array}{l}\text { Non-obese } \\
(n=14)\end{array}$ & $\begin{array}{l}\text { Obese } \\
(n=14)\end{array}$ & $\begin{array}{l}\text { Non-obese } \\
(n=9)\end{array}$ & $\begin{array}{c}\text { Obese } \\
(n=10)\end{array}$ \\
\hline Sex (M/F) & $7 / 7$ & $7 / 7$ & $5 / 4$ & $4 / 6$ \\
Age (years) & $32 \pm 5$ & $29 \pm 5$ & $30 \pm 9$ & $33 \pm 8$ \\
Weight (kg) & $66 \pm 12$ & $157 \pm 29^{\mathrm{a}}$ & $70 \pm 12$ & $144 \pm 21^{\mathrm{a}}$ \\
Height (cm) & $163 \pm 6$ & $168 \pm 8$ & $164 \pm 6$ & $166 \pm 10$ \\
BMI (kg/m $\left.{ }^{2}\right)$ & $25 \pm 4$ & $55 \pm 8^{\mathrm{a}}$ & $26 \pm 3$ & $52 \pm 5^{\mathrm{a}}$ \\
Body fat (\%) & $26 \pm 7$ & $42 \pm 6^{\mathrm{a}}$ & $28 \pm 5$ & $40 \pm 6^{\mathrm{a}}$ \\
Fasting plasma glucose (mmol/l) & $4.7 \pm 0.5$ & $5.3 \pm 0.5^{\mathrm{a}}$ & $4.9 \pm 0.6$ & $5.3 \pm 0.5$ \\
2-h plasma glucose (mmol/l) & $6.3 \pm 1.1$ & $7.3 \pm 1.9$ & $6.3 \pm 1.3$ & $7.5 \pm 2.1$ \\
Fasting plasma insulin (mU/l) & $31 \pm 8$ & $69 \pm 19^{\mathrm{a}}$ & $31 \pm 5$ & $80 \pm 62^{\mathrm{a}, \mathrm{b}}$ \\
2-h plasma insulin (mU/l) & $145 \pm 92$ & $231 \pm 64^{\mathrm{a}}$ & $139 \pm 63^{\mathrm{c}}$ & $320 \pm 198^{\mathrm{a}, \mathrm{c}}$ \\
\hline
\end{tabular}


cytes/SVC of the obese and the non-obese subjects were analyzed using the two-tailed, Student's $t$-test with $p \leq 0.05$ considered significant.

\section{Results}

Of the approximately 45,000 probe sets analysed by microarray hybridisation, 341 probe sets were differentially expressed between the two groups of subjects $(p<0.01)$, as determined by Affymetrix software. Excluding replicate probe sets and genes with unknown functions, 218 genes were annotated as described in the preceding article [3] (Electronic Supplementary Material [ESM] Table 1). The inflammation category consisted of 23 genes, 17 of which were upregulated in obese subjects (Table 2).

We measured the levels of expression of ten representative inflammation-related genes by quantitative RT-PCR in samples of preadipocytes/SVC from an independent group of non-obese and obese subjects. Of the ten genes, six (IL8, CTSS, ITGB2, HLA-DRA, CD53 and PLA2G7) showed significant $(p<0.05)$ differential expression. CCL18 showed a trend $(p=0.07)$ to be upregulated in samples from obese subjects, whereas the levels of expression of ICAM1, CD59

Table 2 Inflammation-related genes

\begin{tabular}{|c|c|c|c|c|c|}
\hline \multirow[t]{2}{*}{ Gene name } & \multirow[t]{2}{*}{ Gene symbol } & \multicolumn{2}{|l|}{ Microarray } & \multicolumn{2}{|c|}{ Quantitative RT-PCR } \\
\hline & & $\begin{array}{l}\text { Fold change } \\
\text { (obese/ } \\
\text { non-obese) }\end{array}$ & $\begin{array}{l}p \text { value of } \\
\text { difference in } \\
\text { expression }^{c}\end{array}$ & $\begin{array}{l}\text { Fold change } \\
\text { (obese/ } \\
\text { non-obese) }\end{array}$ & $\begin{array}{l}p \text { value of } \\
\text { difference in } \\
\text { expression }^{c}\end{array}$ \\
\hline $\begin{array}{l}\text { Chemokine }(\mathrm{C}-\mathrm{C} \text { motif) ligand } 18 \text { (pulmonary and } \\
\text { activation-regulated) }\end{array}$ & $C C L 18^{\mathrm{d}}$ & 2.15 & 0.003 & 5.0 & 0.07 \\
\hline $\begin{array}{l}\text { Phospholipase A2, group VII (platelet-activating factor } \\
\text { acetylhydrolase, plasma) }\end{array}$ & $P L A 2 G 7^{\mathrm{d}}$ & 1.94 & 0.004 & 3.8 & 0.01 \\
\hline Cathepsin S & $\operatorname{CTSS}^{\mathrm{a}}$ & 1.93 & 0.002 & 4.3 & 0.01 \\
\hline Major histocompatibility complex, class II, DR beta 1 & $H L A-D R B 3$ & 1.93 & 0.006 & & \\
\hline Major histocompatibility complex, class II, DR alpha & $H L A-D R A^{\mathrm{d}}$ & 1.78 & 0.009 & 3.6 & 0.05 \\
\hline Macrophage scavenger receptor 1 & MSR1 & 1.73 & 0.008 & & \\
\hline $\begin{array}{l}\text { Integrin, beta } 2 \text { (antigen CD18 (p95), lymphocyte } \\
\text { function-associated antigen 1; macrophage antigen } 1 \\
\text { (mac-1) beta subunit }\end{array}$ & $I T G B 2^{\mathrm{d}}$ & 1.7 & 0.008 & 3.6 & 0.01 \\
\hline Major histocompatibility complex, class II, DQ alpha 1 & $H L A-D Q A 1$ & 1.65 & 0.005 & & \\
\hline $\begin{array}{l}\text { CD74 antigen (invariant polypeptide of major } \\
\text { histocompatibility complex, class II antigen-associated) }\end{array}$ & $C D 74$ & 1.62 & 0.009 & & \\
\hline B cell RAG associated protein & $\begin{array}{l}\text { GALNAC4S- } \\
6 S T\end{array}$ & 1.56 & 0.007 & & \\
\hline CD53 antigen $^{\mathrm{d}}$ & $C D 53^{\mathrm{a}}$ & 1.53 & 0.005 & 2.9 & 0.03 \\
\hline $\begin{array}{l}\text { Decay accelerating factor for complement (CD55, } \\
\text { Cromer blood group system) }\end{array}$ & $D A F^{\mathrm{d}}$ & 1.53 & 0.005 & 1.0 & 0.1 \\
\hline FYN binding protein (FYB-120/130 & $F Y B$ & 1.51 & 0.004 & & \\
\hline Interleukin 8 & $I L 8^{\mathrm{d}}$ & 1.5 & 0.002 & 4.0 & 0.01 \\
\hline Major histocompatibility complex, class II, DM beta & $H L A-D M B$ & 1.45 & 0.008 & & \\
\hline $\begin{array}{l}\text { Intercellular adhesion molecule } 1 \text { (CD54), human } \\
\text { rhinovirus receptor }\end{array}$ & $I C A M 1^{\mathrm{d}}$ & 1.41 & 0.005 & 1.6 & 0.2 \\
\hline Lymphocyte antigen 96 & LY96 & 1.27 & 0.004 & & \\
\hline $\begin{array}{l}\text { Membrane cofactor protein (CD } 46 \text {, trophoblast- } \\
\text { lymphocyte cross-reactive antigen) }\end{array}$ & $M C P$ & -1.19 & 0.005 & & \\
\hline Annexin A11 & $A N X A 11$ & -1.28 & 0.007 & & \\
\hline $\begin{array}{l}\text { CD59 antigen p18-20 (antigen identified by monoclonal } \\
\text { antibodies 16.3A5, EJ16, EJ30, EL32 and G344) }\end{array}$ & $C D 59^{\mathrm{a}, \mathrm{b}, \mathrm{d}}$ & -1.28 & 0.001 & 1.2 & 0.46 \\
\hline T-cell immunomodulatory protein & $C D A 08$ & -1.29 & 0.009 & & \\
\hline Protein $\mathrm{C}$ receptor, endothelial (EPCR) & PROCR & -1.5 & 0.003 & & \\
\hline Cysteine-rich protein 1 (intestinal) & CRIP1 & -3.76 & 0.002 & & \\
\hline
\end{tabular}

The expression levels of the genes in bold font were examined by quantitative RT-PCR

${ }^{a}$ Also differentially expressed in the adipocyte microarray dataset [3] and compared by quantitative RT-PCR in preadipocytes/SVC and adipocytes

${ }^{\mathrm{b}}$ Upregulated in adipocytes and downregulated in preadipocytes/SVC of obese subjects in the microarray experiments

${ }^{c} \mathrm{~A} p$ value $\leq 0.05$ was considered significant

${ }^{\mathrm{d}}$ Genes examined by quantitative RT-PCR 
and $D A F$ were not significantly different between the two groups $(p>0.09)$ (Table 2). In addition, we confirmed the upregulation of $M M P 9$, a gene in the extracellular matrix category that encodes a matrix metalloprotease (microarray, $p=0.005$; quantitative RT-PCR, $p=0.004$ ).

According to the microarray data, only six inflammation-related genes (IL8, CTSS, ITGB2, HLA-DRA, CD53, and $C D 59$ ) were differentially regulated between obese and non-obese subjects in both adipocytes (see ESM Table 1 in [3]) and preadipocytes/SVC (Table 2). In obese subjects, CD59 was downregulated in preadipocytes/SVC and upregulated in adipocytes. We compared the expression levels of the six inflammation-related genes by quantitative RTPCR in the independent groups of subjects (ESM Fig. 1). The results indicated that IL8, CTSS, ITGB2, HLA-DRA and $C D 53$ were significantly upregulated in cultured preadipocytes/SVC of obese subjects; HLA-DRA and CD59 were upregulated in the adipocytes of obese subjects; and $C D 53$ only showed a trend to be upregulated in these samples $(p=0.06)$.

Gene expression levels of macrophage markers (EMRl, $C D 68, C S F 1 R$ and $C C R 2$ ) were also determined by quantitative RT-PCR. Only $C D 68$ expression levels were upregulated $(p=0.05)$ in preadipocytes/SVC of obese subjects. The CSF 1R transcript levels were not different between the non-obese and obese subjects $(p=0.7)$, and expression of $E M R 1$ and $C C R 2$ was not detectable in any subject.

\section{Discussion}

In the present study we have demonstrated that cultured preadipocytes/SVC of obese Pima Indian subjects have elevated levels of expression of inflammation-related genes. This finding highlights the role of preadipocytes/ SVC in adipose tissue inflammation in obesity, similar to the upregulation of inflammation-related genes in isolated adipocytes of obese subjects [3]. Adipocyte microarray gene profiling demonstrated the upregulation of several inflammation-related genes that were not upregulated according to the preadipocyte/SVC microarray data, and vice versa. Of the six inflammation-related genes that were differentially expressed in both adipocyte and preadipocyte microarray profiling experiments, only $H L A-D R A$ was upregulated in both the preadipocytes/SVC and adipocytes of obese subjects. The genes IL8, CTSS, CD53 and ITGB2 were upregulated only in the preadipocytes/SVC of the obese subjects. Other inflammation-related genes that were upregulated in adipocytes of obese subjects, e.g. TNF, IL6, CCL2 (encoding monocyte chemoattractant protein-1), and $C C L 3$ (encoding macrophage inflammatory protein $1 \alpha$ ), were not differentially expressed in preadipocytes/SVC. The results demonstrate cell-specific patterns of activated inflammation-related genes. Preadipocytes/SVC and adipocytes may play different, but complementary, roles in obesity-related inflammation. However, we cannot rule out the possibility that the differences we observed were due, at least in part, to differences between freshly isolated and cultured cells.
The gene encoding the chemokine IL-8 (IL8) was upregulated in cultured preadipocytes/SVC of obese subjects in this study. Our data support previous work $[9,10]$ indicating that IL-8 levels secreted by non-adipocyte cells in human adipose tissue correlate positively with BMI. The proinflammatory IL- 8 upregulates the expression of MMP9, a Type IV matrix metalloprotease involved in extracellular matrix remodelling in adipose tissue $[11,12]$. As expected, MMP9 expression was elevated in preadipocytes/SVC of obese subjects compared with those of nonobese subjects. Both MMP9 and IL-8 are involved in leucocytosis and stem cell mobilisation [13]. Thus, we hypothesise that the IL-8 and MMP9 secreted by the preadipocytes/SVC may play a role in extracellular matrix changes or adipose tissue remodelling. The remodelling may be required to accommodate adipose tissue expansion and/or recruitment of immune cells into the tissue.

Inflammation-related genes can also be expressed by macrophages; thus, we examined whether the increased expression of these genes in cultured preadipocytes/SVC from obese subjects was due to the presence of potentially contaminating macrophages. Only one (CD68) of the four macrophage markers tested was upregulated in cultured preadipocytes/SVC of obese subjects. These data need to be further corroborated by other methods, such as immunohistochemistry. Nevertheless, the results indicate that although macrophages may be present in the preadipocyte/ SVC cultures, they are not likely to be a major contaminant. Thus, we suggest that other cell types in the cultures, probably the preadipocytes/SVC themselves, are the major contributors to the elevated expression of inflammationrelated genes.

Collagenase digestion of adipose tissue during isolation of preadipocytes/SVC could potentially stimulate transcription of inflammation-related genes; however, this is rather unlikely. After culturing the cells for at least $48 \mathrm{~h}$, the inflammatory state of preadipocytes/SVC (as assessed by the expression of pro-inflammatory genes $T N F$ and $I L 1 B$ ) should return to the level observed prior to collagenase digestion (X. Xu and A. Ferrante, Naomi Berrie Diabetes Center, Columbia University, NY, USA, personal communication).

To summarise, increased expression of inflammationrelated genes in cultured preadipocytes/SVC from obese individuals indicate that these cells, like adipocytes, may contribute to adipose tissue inflammation associated with obesity.

Acknowledgements We gratefully acknowledge the Pima Indian community for their participation, and the clinical staff for the care of the research volunteers.

\section{References}

1. Bruun JM, Pedersen SB, Richelsen B (2001) Regulation of interleukin 8 production and gene expression in human adipose tissue in vitro. J Clin Endocrinol Metab 86:1267-1273 
2. Fried SK, Bunkin DA, Greenberg AS (1998) Omental and subcutaneous adipose tissues of obese subjects release interleukin-6: depot difference and regulation by glucocorticoid. J Clin Endocrinol Metab 83:847-850

3. Lee Y-H, Nair S, Rousseau E et al (2005) Microarray profiling of isolated abdominal subcutaneous adipocytes from obese vs non-obese Pima Indians: increased expression of inflammation-related genes. Diabetologia 48:DOI 10.1007/s00125-0051867-3

4. Weisberg SP, McCann D, Desai M, Rosenbaum M, Leibel RL, Ferrante AW Jr (2003) Obesity is associated with macrophage accumulation in adipose tissue. J Clin Invest 112:1796-1808

5. Xu H, Barnes GT, Yang Q et al (2003) Chronic inflammation in fat plays a crucial role in the development of obesity-related insulin resistance. J Clin Invest 112:1821-1830

6. Charriere G, Cousin B, Arnaud E et al (2003) Preadipocyte conversion to macrophage. Evidence of plasticity. J Biol Chem 278:9850-9855

7. Cousin B, Andre M, Casteilla L, Penicaud L (2001) Altered macrophage-like functions of preadipocytes in inflammation and genetic obesity. J Cell Physiol 186:380-386

8. Permana PA, Nair S, Lee YH, Luczy-Bachman G, Vozarova De Courten B, Tataranni PA (2004) Subcutaneous abdominal preadipocyte differentiation in vitro inversely correlates with central obesity. Am J Physiol Endocrinol Metabol 286:E958E962
9. Bruun JM, Lihn AS, Madan AK et al (2004) Higher production of IL-8 in visceral vs subcutaneous adipose tissue. Implication of nonadipose cells in adipose tissue. Am J Physiol Endocrinol Metabol 286:E8-E13

10. Fain JN, Madan AK, Hiler ML, Cheema P, Bahouth SW (2004) Comparison of the release of adipokines by adipose tissue, adipose tissue matrix, and adipocytes from visceral and subcutaneous abdominal adipose tissues of obese humans. Endocrinology 145:2273-2282

11. Mulayim N, Savlu A, Guzeloglu-Kayisli O, Kayisli UA, Arici A (2004) Regulation of endometrial stromal cell matrix metalloproteinase activity and invasiveness by interleukin- 8 . Fertil Steril 81(Suppl 1):904-911

12. Bouloumie A, Sengenes C, Portolan G, Galitzky J, Lafontan M (2001) Adipocyte produces matrix metalloproteinases 2 and 9: involvement in adipose differentiation. Diabetes 50:2080-2086

13. Starckx S, Van den Steen PE, Wuyts A, Van Damme J, Opdenakker G (2002) Neutrophil gelatinase B and chemokines in leukocytosis and stem cell mobilization. Leuk Lymphoma $43: 233-241$ 